Chapter IV

Conclusion 



\section{Comparing Violence in Asia and Europe - A Contribution to Solving a Complex Problem}

\section{La Toya Waha}

In the chapters of this volume, a variety of cases of violence in Asia and Europe as well as a diversity of explanations for violence have been presented. While violence and its emerging conditions stood in the focus, the presented cases transcended phenomenal domains and local particulars. The challenge the analyses pose to disciplinary foci and singular explanations may further the scientific discourse as well as the interdisciplinary exchange.

However, understanding the emergence of violence is not just of scientific interest. The relevance and the necessity to understand violence present themselves almost daily in the news. Not the least when we look at the consequences, the Islamist attacks in Sri Lanka in April 2019 had, the need for political decision makers' better understanding of the phenomenon becomes clear.

\section{Relevance to Understand Violence beyond Science: The Impact of the Islamist} Attacks 2019

The need to understand violence better shall be shortly pointed out by looking at some of the consequences, the Islamist attacks in 2019 had for Sri Lanka. These include, among others, the outbreak of violence between different religious communities, the (re-)emergence of religious figures as political leaders and the likely societal conflict arising from the resulting contention about the values of the state, and the impact of the security issues' dominance on political decision making.

The aftermath of the Islamist attacks in Sri Lanka in April 2019 has seen rising influence of religious figures within the different communities. One of the most notable examples for this might be Cardinal Malcolm Ranjith, archbishop of Colombo. ${ }^{1}$ He took the lead of the Catholic community and became stylised as the 'Christian voice' in the emerging conflict. Although

1 This Week in Asia, 12 May 2019. 
his calls for restraint and calm could not prevent retaliatory violence against Muslims in the regions where the attacks had happened, he became a key figure in criticising and commenting political decisions. While his critique of the government has not started with the attacks, he was heard much more than before. Even more, his suggestions for action as well as his frequent call for peace among the Sri Lankan people has gained him the trust beyond religious divides and led some to call for his presidency. These calls have not been heard; however, his influence in politics has significantly increased. While in the case of Cardinal Malcolm Ranjith a religious leader has emerged, who seems unlikely to mobilise on religious lines for political gains, his significant influence among the population and the calls for him to become president point towards the danger of conflating religious and political leadership. The merging of religious authority and political office prohibits the criticism of decisions made by the leaders, or the leaders' behaviour itself. A short perusal of Sri Lanka's history of Buddhist monks in politics serves as a case in point. Even beyond this, the centrality of religious figures in politics is prone to conflict in a society with adherents to diverse religions. The influence of a Christian figure is likely to provoke a response by radical Buddhists. Such tensions then do not remain between political agents. They spread into the community and thus might challenge the fragile trust between Christians and Buddhists which has rebuilt over decades. This development appears to prevent the shift from identity politics to ordinary politics. Religious figures in politics thus further, to use Mitra's terms, the politics of the system rather than politics within the system.

Moreover, in the consequence of the Islamist attacks, retaliatory attacks, violent clashes and counter-strikes involving members of the Muslim community have become more frequent. Conflicts, which started as disputes on Facebook, have escalated into violence between communities; people took 'justice' into their own hands, and attacked a mosque as demands to search the mosque for weapons have not been met; Muslim shops became target of angry crowds. While the government responded quickly and implemented diverse measures to end the violence - curfews, arrests, blocking of social media, to name a few - the tensions between the members of different communities remain. Religion has gained a new presence in the public sphere, and boundaries along religious lines are drawn more visibly since the Easter Sunday attacks.

After the Islamist attacks, the trust between the communities has further declined. So has the trust in Muslim politicians due to their alleged - and 
confirmed - ties to the terrorists and their supporters. ${ }^{2}$ The trust in Muslim politicians had been on a downward trend among the Muslim population before, enabling new actors to take the political lead of the community, at least in some parts of the country (Waha 2018:332f.). The trust by members of the Muslim community as well as the trust in Muslim politicians by members of the other communities has taken severe damage. As Muslim political parties have been long regarded as king/queen maker in Sri Lankan politics (Wickramasinghe 2014:198, 166, 381), the likely change in electoral support for Muslim parties can impact the power politics in Sri Lanka.

Even more, the Islamist attacks had an impact on the presidential elections which were held in November 2019. The allegations that members of the serving government, including the president and the prime minister, had not taken warnings by the Indian intelligence seriously, which could have prevented the deadly attack, the support for the then incumbent government coalition further declined. ${ }^{3}$ Although the inability to uphold the functioning of the security apparatus and process of intelligence information have not been the first or sole reason for it, the handling of the threat, or better the lack thereof, has promoted the call for a strong leader, able to restore security and order in the country. As such, the attacks propelled the issue of security on the top of election campaigns and agendas. In the field of security and the dealing with terrorism, none of the presidential candidates could present as much experience and credentials as Gotabaya Rajapaksa, a central figure of the military defeat of the Liberation Tigers of Tamil Eelam in 2009. Yet, the issue of security has delegated the questions of good governance, reconciliation and distancing from China and its debt-trap to the sideline. And while Gotabaya Rajapaksa appears to be able to solve problems as a technocrat, his political career is accompanied by his elder brothers, most notably, former president Mahinda Rajapaksa, whose records for good governance, rule of law and accountability are not quite good (Goodhand 2013). The costs of bringing (indirectly) Mahinda Rajapaksa, who stands for authoritarian rule, nepotism and the sell-out of Sri Lanka to China, back to power were willingly taken for the sake of re-establishing security. While Gotabaya Rajapaksa has not won the elections just because of the attacks, his credentials as strong man and capable of bringing back security for some voters surely have tipped the scale.

2 See among others The Diplomat, 4 June 2019.

3 The Guardian, 24 October 2019. 
Finally, the attacks have severely impacted one of Sri Lanka's central economic pillars - tourism. The numbers of tourists have significantly declined since the attacks and as such the income generated by tourism and tourism-related fields. ${ }^{4}$ It has again not just been the attack, which had led the Sri Lankan economy to stumble - politicians' mismanagement and self-interest, such as during the political crisis at the end of 2018 (Echle 2018), had taken its toll on the Sri Lankan economy, too. But the attacks have furthered the decline of a successful income generator. This downward trend has continued, leading to one of the country's lowest growth rates, even underdoing those during the civil war. Thousands of substances have been destroyed.

The case of Sri Lanka shows that the relevance of understanding the way towards violence is not limited to science. Instead, the understanding of how violence of this kind emergences and thus the ability to act meaningfully - or the lack thereof - can have an impact on state and society - and thus potentially on the life of every individual. While the most obvious reason for politicians to care about potential counter-measures is the prevention of death, injury and destruction of citizens and property, it, too, is in their interest to prevent the negative consequences affecting far more than those, who lost their lives, their health or their loved ones in the attack itself. The spread of networks and ideologies accompanying the violence in one country may reach deep into the social structures and families elsewhere, facilitating and furthering violence in yet another country, as Rahman has shown above. Beyond that, developments in one country affect the spread of violence elsewhere. Clashes between members of different communities are frequently used politically to point to an emerging faultline war à la Huntington. Particularly the IS has drawn hundreds into its ranks with the narrative of a world-wide victimised community under threat and the constructed claims of large-scale discrimination and assault. McDonald has pointed out the importance of distant suffering in the individual's way towards engagement in violence. Moreover, as Barton and Gunaratna have shown in this volume, the conflict zones in one country facilitate the emergence of conflicts elsewhere.

As Sri Lanka and the cases presented above show, violence can severely challenge the fundaments of states and societies, the complex social fabric, the trust among different communities within a country and beyond, and the retainment of nuances in politics - nationally, regionally, and globally.

4 The Diplomat, 31 July 2019. 
Ill-conceived policies and uninformed political decisions might cut deep into the freedoms and rights of citizens and the rule of law and might go against the value fundaments of the society as whole. As Croissant has pointed out in this volume, the potential "democratic backsliding" itself can further the spread of violence. Successful and unsuccessful means to rule-in radical and violent political agents have been shown on the examples of India and Pakistan by Mitra and Iqbal respectively in this book.

But what lessons can be drawn from this volume about the way towards violence by non-state actors in general, and responses and means of prevention beyond single cases?

To provide an answer has been the rationale behind the workshop, in which most of this volume's authors and participants of the conference came together. In different sessions, one question respectively was discussed. Each session was led by a moderator, who came in as expert from a related field or discipline. In each session, the participants were divided into two groups. Each group independently from the other group answered the question given for the session. Thereby, the group members documented the thought- and group-discussion processes in writing. Thereafter, the groups exchanged their papers with the documented processes and discussed the given results. In the final part of the session, the treated points were discussed in plenum and the results of the debate - points on which the participants could agree upon - were collected by the moderator. This approach was an experiment and was supposed to get as much out of the interdisciplinary exchange as possible on the one hand, and out of the individual expertise and knowledge, on the other hand. Although this method cannot replace a systematic comparison of cases and disciplinary approaches, it can provide on overview over directions, research may take. The results of the two major sessions are given in the following.

\section{Similarities and Differences}

The compared cases of violence applied by non-state actors differ in regional and cultural context, in timing as well as in ideological and/or religious background. However, there are elements the treated cases share.

First, the application of violence is intentional and serves a purpose. Violence is neither random, nor does it come out of nowhere. There is a process, even if of different length and intensity, which precedes the application of violence. Violence thus is not an outcome unplanned or unintended by the perpetrating agent but is used towards an end, result or aimed-at outcome. This finding thus goes against the framing of radicalisation - un- 
derstood as the process towards violence - as "something done to a person" (see McDonald above). It 'brings back' the agency to individuals and groups involved in violence.

Second, the spread of violence takes place in a context, where violence is 'normalised', i.e. where the application of violence becomes the norm, rather than the exception. Such acceptance of violence thus allows for the spread of the use of violence for political and social ends. On the other hand, the rejection of violence and the lack of support for violent behaviour can negatively affect the strategic value of physical force, the supply with resources for violent actors as well as the incentives to join a violent campaign.

Third, the violence perpetrated is visible, and as such makes the agent visible. This stands in a sharp contrast to the invisible violence perpetrated in the domestic sphere or by certain states and regimes. The participants pointed towards the salient contrast between the visible attacks, such as in Sri Lanka, planned for the world to see, and clandestine violence hidden from the world's eyes, such as in the Nazi regime. Thus, the message behind the violent act might give conclusions about the intended outcome.

Fourth, the cases share the importance of the interplay between the local and the global. Neither local nor global developments solely explain the emergence and continuation of violence in the presented cases. Instead, they suggest an interdependence between global and local events.

Fifth, the violence is related to (collective) identities - although of various kinds. These identities can be 'filled' by religion, ethnicity or secular ideologies as well as a peculiar combination thereof.

Sixth, the process of the emergence of violence involves all three levels, the micro, the meso and the macro - and all three levels matter in understanding the emergence of violence even in pronounced local, regional or global contexts. As such, the individual, the group or collective as well as the national and international structural and political conditions play into the process. Taking measures, thus, requires an encompassing approach, rather than the focus on 'just' one level.

Despite the similarities, the differences should not be neglected. The five major differences identified are the following. First, there are differences in what the violence is intended to do. Thereby, it can be differentiated mainly between performative violence and instrumental violence. While both kinds of violence are instrumental in terms of being a means towards an end, instrumental violence in this context refers to the means towards the end of physical destruction e.g. of critical infrastructure and opponents, while the performative violence seeks to achieve a more sym- 
bolic end, such as conveying a message about the victim or the perpetrator or both.

Second, violence emerges in different contexts of interaction between state and non-state actors. At times violence emerges with state's support for non-state actors' behaviour, in other cases it emerges in the context of a state's repression of non-actors, and in yet other cases, it emerges in the context of contention between state and non-state actors. Furthermore, the relations between state and non-state actors differ in quality and origin e.g. internal non-state actors vs. external or transnational agents.

Third, the question of 'who is to be blamed' for the use of violence is answered differently in different contexts. This refers both to the non-state actors' answer to the question as well as to the state's and societies' answer to it. However, differences therein can make a significant difference for the agents themselves as well as for their supporting environment.

Fourth, there are great differences in what was termed 'ideological crossover support'. While there appear to be differences and similarities in ideological content in all of the cases, it appears that while some actors of different phenomenal domains have not been found to cooperate, others have appeared to be more likely to lend support to agents with other ideological backgrounds. It was found that extreme left-wing groups appear to be more likely to lend support - although counter-intuitive - to extremist religious groups than groups of the other phenomenal domains do to others.

Fifth, there are differences in identity lines, that is, how the lines of delineation towards other groups are drawn. Even in cases where groups nominally share a similar ideological background, identity lines can be differently defined and nuanced.

Disputed was whether the discussed cases shared the 'narrative of replacement'. While some argued that it only played a role in ethnic and religious phenomena, and mainly in the case of radicalisation of majorities, some claimed that this conviction could be found in groups with other (secular) ideological backgrounds as well.

\section{Recommendations - How to Prevent Violence?}

It was found that there are similarities in the processes towards violence as well as the application of violence between the cases presented above. Some of the similarities lend themselves to the drawing of conclusions and recommendations of how to prevent violence in the context given in the book. 
In general, the need to engage at all three levels (micro, meso and macro) at the same time and in a coordinated manner was pointed out. Due to the complexity and multi-dimensionality of the radicalisation process, i.e. the way towards violence, the counters and responses to it need to be multi-dimensional as well. And as agents acting at the different levels matter, like individuals, friends, families, groups, transnational networks, politicians and international agents, those different agents need to be considered in political decisions. Focusing on one level only will not suffice to prevent and counter violence on the long run. It includes the targeting of individuals, groups and communities as well as international organisations and agents in measures to prevent and/or to end violence. In national measures for prevention, the major target groups were identified as the community, those on the path to radicalisation and those already involved in an act of terror. For the first two categories, the need for education, the need to build societal cohesion and the need to counter narratives of violence and their preachers were stressed. Thereby, particularly with regard to the role of the normalisation of violence in its spread, it is arguable that state-agents should seek to prevent the normalisation of violence and to uphold non-violent means of engagement within politics and the society. Laws against the spread of violent extremism as well as community responses to violent acts and violence-promoting messages were regarded as basic requirements.

For those, who already engaged in violence, there is the need to demonstrate the boundaries for their actions. If imprisoned, however, the necessities of educating prisoners in life-skills and non-violent means of problem solving and, if possible, providing prospects for reintegration into the society were pointed out.

The translation of these overriding recommendations into concrete measures, however, has met its limits in the diversity of political systems and societal values. For example, the state's role as social engineer was acknowledged, but its concrete meaning highly contested. Should the state censure public debate and social media and determine the 'right' religious teaching? While in some states and societies these measures appear to be acceptable, what about the central values of pluralistic societies and the rights given in liberal democracies? At the same time, the role of civil society organisations in providing complementary measures to those of the state were recognised. But the extent to which these organisations could provide alternative approaches and act independently from the state widely varied. A further recommendation to recognise societal conflict, but to provide platforms to creatively discuss the issue at hand without violence, too, finds a limit in different political systems and their values. Govern- 
ments of authoritarian states dominated by one political party are unlikely to accept the recommendation to channel interests through diverse political parties to allow for a non-violent negotiation of issues.

The discussion of concrete means translating the findings into policies, thus, has shown the limitations to providing generally applicable policy recommendations. While the direction of what needs to be done appears to be shared and clear, the concrete measures are not. The acceptance of measures which might work well in one political and social context can challenge the social and political fundaments of others.

To sum up, while the finding that the way towards violence involves all three levels (the micro, the meso and the macro level) is crucial for the formulation of recommendations for a meaningful response to violence and its prevention, it does not suffice for the translation into concrete policy recommendations. The way towards violence as well as its successful countering are multi-dimensional and despite shared characteristics of cases, no broad-spectrum antibiotic can be provided here. The debates among the workshop members on measures for diverse societies and political systems have shown that what might work in one country challenges the very fundaments of the other. Even more, the transplanting of one into the other is doomed to fail - as many earlier examples suggest. This leads to the conclusion that the countering of non-state agents' violence is too complex for a concrete all-time solution.

What, then, is the use, the value of this book?

The treatment of non-state actors' way towards violence has shown the complexity of the problem at hand. A number of variables plays into the process, some of these variables are connected to one another, in one way or the other, and more often than not, the connections and links between them are not clearly transparent. Even more, the issue at hand is not static, but evolves constantly. And given the unclarity of what radicalism (or extremism) is, when and if violence is acceptable, when and if legitimate or condemnable, more often than not it is unclear what concrete end political agents aim at. ${ }^{5}$ The prevention and overcoming of violence by non-state actors, thus, is a complex problem. Characteristic for such problems is that

5 What seems to be a simple answer might get challenged by the question of whether the attempted assassinations of Adolf Hitler, classifiable as both radical and extremist, were legitimate. 
the start state or point of departure, the features of the intended goal state, and features of the barriers standing between them are unknown, prove complexity, change dynamically over time and linkages between them are partially intransparent (Funke 2012:683).

The solution, thus, requires decision makers capable of complex problem solving. Successful complex problem solving thereby has been found to share certain features, which remain equal in differing social or political contexts. These features relate to the following decision making process: 1) information gathering, 2) model building, 3) goal elaboration and balancing, and 4) agent's elaboration of plans and means (Funke 2010:136-137). Information gathering thereby refers to the collection of information about the systems in which the complex problem needs to be solved in and model-building implies the integration of "this information into [a] model of the system", i.e. the attempt to more systematically understand the environment (ibid.).

The issue with complex problems, next to their dynamic development, is that decision makers know too little about the relation between the different variables involved. Often, decision makers fail in solving problems as they are unable to systemise the immense available information into an appropriate model of the system. For the successful solution of complex problems information, thus, not only need to be gathered, but also systematised.

This book sought to provide insights into different cases and explanatory approaches of non-state actors' violence and to spark a new interdisciplinary debate in order to enable a more thorough understanding of the phenomenon. The task is not yet complete, but the first step into the direction is done. The book has provided information and furthered the multidimensional understanding of the issue. As such, the present information might allow for more profoundly building a model of the system, needed for successfully solving the complex problem at hand. This is the contribution of this book to approaching the issue of non-state actors' violence.

\section{References}

Echle, Christian. 2018. "Regierungskrise in Sri Lanka". KAS Länderberichte, 7 November 2018.

Funke, Joachim. 2003. Problemlösendes Denken. Stuttgart: Kohlhammer.

Funke, Joachim. 2010. "Complex Problem Solving: A Case for Complex Cognition?”. Cognitive Processing, 11: 133-42. 
Funke, Joachim. 2012. “Complex Problem Solving”. In: Seel, N.M. ed. Encyclopedia of the Sciences of Learning. Boston: Springer. Doi: 10.1007/978-1-4419-1428-6_685.

Goodhand, Jonathan. 2013. "Sri Lanka in 2012: Securing the State, Enforcing the 'Peace". Asian Survey 53 (1): 64-72.

Huntington, Samuel, P. 1993. "The Clash of Civilizations?” Foreign Affairs, 72 (3): 22-49.

McDonald, Kevin. 2018. Radicalization. Cambridge: Polity Press.

The Diplomat. 2019. "Easter Bombings Damaged Sri Lanka Economy Beyond Tourism”. 31 July 2019. (https://thediplomat.com/2019/07/easter-bombings-dam aged-sri-lanka-economy-beyond-tourism/). Accessed 21 February 2020.

The Diplomat. 2019. "Easter Bombings Damaged Sri Lanka Economy Beyond Tourism”. 31 July 2019. (https://thediplomat.com/2019/07/easter-bombings-dam aged-sri-lanka-economy-beyond-tourism/). Accessed 21 February 2020.

The Diplomat. 2019. "Muslims Politicians Resign Top Sri Lankan Government Posts Amid Terror Probe”. 4 June 2019. (https://thediplomat.com/2019/06/musli ms-politicians-resign-top-sri-lankan-government-posts-amid-terror-probe/). Accessed 21 February 2020.

The Guardian. 2019. "Sri Lanka bombings: spy chief lambasted in damning report 24 October 2019”. (https://www.theguardian.com/world/2019/oct/24/sri-lanka-s py-chief-blamed-for-failures-over-easter-bombings). Accessed 14 March 2020.

This Week in Asia. 2019. “'Voice of The Nation': As Sri Lanka Loses Faith in the Government, It Looks to a Cardinal for Leadership". 12 May 2019. (https://www .scmp.com/week-asia/opinion/article/3009577/voice-nation-sri-lanka-loses-faith-g overnment-it-looks-cardinal). Accessed 21 February 2020.

Waha, La Toya. 2018. Religion and State-Formation in Transitional Societies: Sri Lanka in a Comparative Perspective. Baden-Baden: Nomos.

Wickramasinghe, Nira. 2014. Sri Lanka in the Modern Age - A History. New York: Oxford University Press. 
